\title{
INTERCULTURALIDADE NA ESCOLA PÚBLICA DE SÃO PAULO
}

\author{
Elbio Miyahira ${ }^{1}$ \\ Karoline Rezende Sayar ${ }^{2}$
}

\begin{abstract}
Resumo:
Este texto procura analisar como se dá a relação entre os estudantes imigrantes bolivianos ou filhos de bolivianos e os estudantes brasileiros em uma escola pública da cidade de São Paulo e como a escola trabalha essa questão. Pesquisas anteriores demonstraram que havia uma grande indiferença à presença dos alunos imigrantes por parte dos professores e da direção em algumas escolas públicas de São Paulo. Com isso não havia uma ação pedagógica específica para tratar as particularidades dos imigrantes. Também não se buscava regular a relação entre os grupos evitando a prática de bullying e, muito menos, se buscava promover uma integração entre os grupos. Realizou-se a observação de classe durante quatro semanas seguidas em duas turmas (oitavo e nono anos) de uma escola estadual da região central da cidade de São Paulo. Verificou-se que a escola observada criou um ambiente multicultural, no sentido de desenvolver uma convivência mais pacífica entre as diferentes culturas, mas ainda não conseguiu construir um ambiente de interação e integração entre os grupos. Constatou-se a utilização de práticas pedagógicas que contribuem para a convivência entre os grupos, mas verificou-se que ainda há muitas ações que poderiam ser desenvolvidas.
\end{abstract}

Palavras-chave: Multiculturalismo. Interculturalismo. Imigração. Imigrante boliviano. Escola pública. São Paulo.

\begin{abstract}
:
This paper seeks to analyze the relationship between students who are Bolivian immigrants or the children of Bolivian immigrants and Brazilian students in a public school in São Paulo and how the school addresses this situation. Prior studies have shown that the teachers and the administration are largely indifferent to the presence of immigrant students in the some of publics schools of São Paulo city. Thus, there have been no specific pedagogical actions to deal with the particularities of the immigrants, nor has there been any attempt to manage the relationship between the groups to avoid the practice of bullying and, even less so, to promote integration between them. Classroom observation was conducted in two classes (8th and 9th grade) for four consecutive weeks in a state school in the central region of the city of São Paulo. It was found that the school observed has made advances in creating a multicultural environment, creating a more peaceful coexistence between the different cultures, but has not yet succeeded in building an environment of interaction and integration between the groups. The use of pedagogical practices that help foster coexistence between the groups was observed; however, there are still several actions that could be developed.
\end{abstract}

Keywords: Multiculturalism. Interculturalism. Immigration. Bolivian immigrants. Public school. São Paulo.

\footnotetext{
${ }^{1}$ Mestre em Educação pelo Programa de Educação: História, Política, Sociedade da PUC-SP, atualmente doutorando do mesmo Programa.

${ }^{2}$ Mestre em Educação pelo Programa de Educação: História, Política, Sociedade da PUC-SP.
} 


\section{Introdução}

O Estado de São Paulo é o local onde há a maior concentração de imigrantes no Brasil e, dentre as cidades deste estado, a cidade de São Paulo é a cidade onde os imigrantes estão mais presentes. Esse fato impacta as escolas, principalmente as escolas públicas onde se concentra a maior parte desses alunos imigrantes. No ano de 2019, segundo dados da Secretaria de Educação do Estado de São Paulo, tivemos 18.200 alunos imigrantes nas redes públicas (municipais, estadual e federal) dentro do Estado de São Paulo e 8.665 alunos imigrantes na rede particular do Estado de São Paulo.

Dentre os grupos de imigrantes nas escolas públicas de São Paulo, o maior grupo é o de bolivianos. Porém, algumas pesquisas demonstram que as escolas públicas analisadas se colocam de forma indiferente à presença desses alunos imigrantes. Portanto, este tex to procura analisar se essa indiferença também se dá em uma escola específica da rede estadual na região central da cidade de São Paulo.

O texto inicia com uma análise dos dados estatísticos de alunos imigrantes nas escolas da rede pública de São Paulo e depois especificamente trabalha com dados estatísticos dos alunos bolivianos. Na segunda parte, o texto descreve a escola analisada. Na terceira, analisa as práticas pedagógicas e as relações estabelecidas pelos grupos dentro da escola observada. $\mathrm{Na}$ quarta e última parte, tece algumas considerações com base nos dados analisados.

\section{Dados da imigração em São Paulo}

Segundo dados da Secretaria de Educação do Estado de São Paulo, o maior grupo de imigrantes nas escolas públicas do estado são os bolivianos (tabela 1).

\section{Tabela 1}

Números de alunos imigrantes nas escolas públicas do Estado de São Paulo.

\begin{tabular}{lllll}
\hline \multirow{2}{*}{ País de origem } & \multicolumn{2}{l}{ Escolas } & \\
\cline { 2 - 4 } & estadual & municipal & federal & Total \\
\hline Bolívia & 4995 & 1865 & 0 & 6.860 \\
Japão & 1387 & 726 & 0 & 2.113 \\
Haiti & 923 & 1072 & 0 & 1.995 \\
Angola & 580 & 249 & 0 & 829 \\
Colômbia & 354 & 314 & 0 & 668 \\
Paraguai & 464 & 186 & 0 & 650 \\
Peru & 492 & 136 & 0 & 628
\end{tabular}


Cadernos CERU, Série 2, Vol. 31, n. 1, jun. 2020

\begin{tabular}{lllll} 
Portugal & 300 & 284 & 0 & 584 \\
Argentina & 294 & 154 & 0 & 448 \\
Venezuela & 204 & 172 & 0 & 376 \\
Espanha & 124 & 153 & 0 & 277 \\
Síria & 119 & 124 & 0 & 243 \\
EUA & 131 & 110 & 1 & 242 \\
Nigéria & 120 & 56 & 0 & 176 \\
China & 108 & 60 & 0 & 168 \\
Chile & 89 & 56 & 0 & 145 \\
Cuba & 53 & 62 & 0 & 115 \\
Itália & 51 & 63 & 0 & 114 \\
Equador & 84 & 28 & 0 & 112 \\
Outros & 907 & 550 & 0 & 1.457 \\
\hline Total & 11.779 & 6.420 & 1 & 18.200
\end{tabular}

Fonte: Secretaria $\overline{\text { de Educação do Estado de São Paulo - Data base: }}$ 03/2019 - Dados organizados por E. Miyahira.

Verifica-se na tabela 1 que 6.860 (37,69\%) alunos da rede pública do Estado de São Paulo são bolivianos. Em segundo lugar, temos os japoneses com $2.113(11,61 \%)$ e, em terceiro lugar, os haitianos com 1.995 (10,69\%). Ou seja, os bolivianos são mais de três vezes o número de alunos do segundo maior grupo e são mais do que o segundo e o terceiro maiores grupos juntos. Esses dados não levam em consideração os filhos de imigrantes já nascidos no Brasil, pois esses são contabilizados como brasileiros e, infelizmente, o governo não dispõe de dados estatísticos sobre a nacionalidade dos pais de alunos da rede pública. A obtenção desses dados só é possível analisando os prontuários de cada aluno em cada uma das escolas onde os mesmos estudam.

Se analisarmos a distribuição dos alunos imigrantes bolivianos por cidades do Estado de São Paulo, vemos que a cidade de São Paulo é o município onde se concentra o maior número de alunos imigrantes bolivianos (tabela 2).

Tabela 2

Número de alunos imigrantes bolivianos nos municípios do Estado de São Paulo.

\begin{tabular}{lc}
\hline Cidade & no. alunos \\
\hline São Paulo & 5.012 \\
Guarulhos & 467
\end{tabular}




\begin{tabular}{lc} 
Itaquaquecetuba & 236 \\
Carapicuíba & 209 \\
Americana & 100 \\
Osasco & 96 \\
Franco da Rocha & 70 \\
Itaí & 58 \\
Barueri & 53 \\
Bady Bassit & 41 \\
Outros municípios & 518 \\
\hline Total & 6.860
\end{tabular}

Fonte: Secretaria de Educação do Estado de São Paulo - Data base: 03/2019 - Dados organizados por E. Miyahira.

A grande maioria dos alunos imigrantes bolivianos, 5.012 alunos (73,06\%), localiza-se no município de São Paulo. Ou seja, a cidade de São Paulo acolhe aproximadamente três vezes o número de alunos bolivianos de todas as outras cidades do Estado de São Paulo juntas. Se considerarmos a Grande São Paulo, essa concentração é ainda maior, pois, dentre as dez cidades com maior quantidade de alunos bolivianos, sete municípios são da Grande São Paulo (São Paulo, Guarulhos, Itaquaquecetuba, Carapicuíba, Osasco, Franco da Rocha e Barueri) e somente três cidades fora da Grande São Paulo (Americana, Itaí e Bady Bassit). As cidades da Grande São Paulo juntas têm 6.143 alunos bolivianos $(89,54 \%)$.

Dentro da cidade de São Paulo, vemos que há alunos bolivianos na rede pública em todos os distritos da cidade, porém com uma concentração maior na região central e nos distritos ao norte e a leste da região central: Mooca, Vila Maria, Penha, Casa Verde e Sé (mapa 1). 


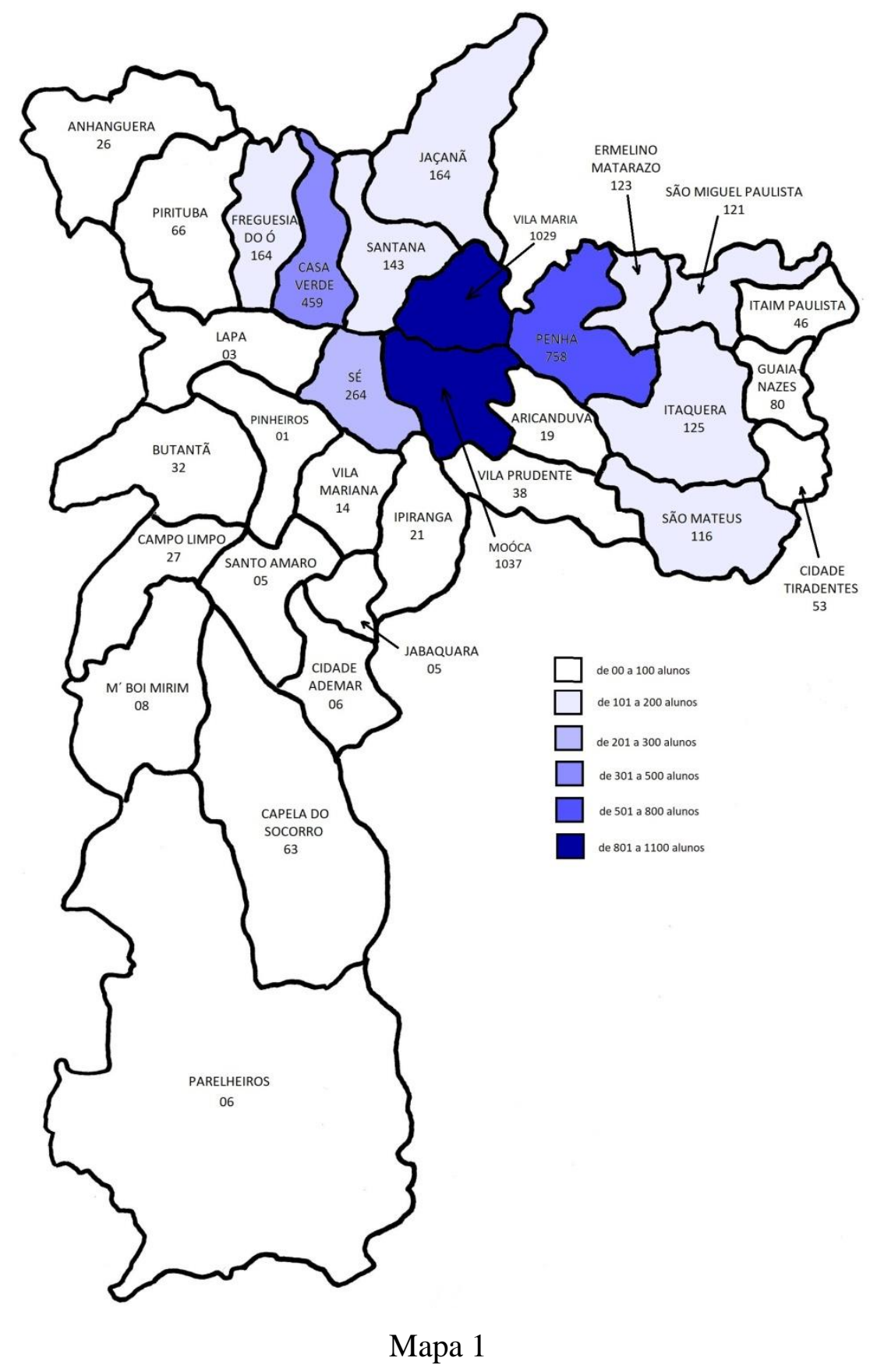

Número de alunos bolivianos na rede pública por distrito.

Fonte: Secretaria de Educação do Estado de São Paulo - Data base: 03/2019 - Dados organizados por E. Miyahira.

A dispersão dos imigrantes bolivianos pela cidade de São Paulo e municípios vizinhos tem ligação com as importantes transformações que o mercado da costura passou nas últimas cinco décadas. Até a década de 1970, o mercado têxtil tinha como características: forte separação entre comércio e indústria, alto grau de formalização das relações de trabalho e tendência à verticalização da produção nas fábricas (XAVIER, 2012). A partir das décadas de 1970 e 1980, várias transformações ocorreram: surgiram avanços tecnológicos na produção e 
Cadernos CERU, Série 2, Vol. 31, n. 1, jun. 2020

as fábricas perderam tamanho, passando a serem de médio e pequeno porte. As fábricas começaram a se concentrar somente na criação, modelagem, corte de tecido e comercialização dos produtos. A costura passou a ser terceirizada para oficinas externas, diminuindo os empregos formais e espalhando as oficinas principalmente nas áreas periféricas da cidade (XAVIER, 2012). Nas últimas duas décadas, os imigrantes bolivianos que sempre estiveram, em sua grande maioria, ligados à área de costura, começaram a abrir suas próprias oficinas em uma sala de sua residência, de forma irregular, e espalhadas por São Paulo. A ida para diversos distritos foi motivada pelo menor custo do aluguel.

\section{A escola pesquisada}

Com base nesses dados que nos mostram que a maior concentração dos alunos bolivianos na rede pública está na região central e distritos próximos à mesma em direção à região leste e norte, foi efetuada a observação em classe em uma escola da região central da cidade de São Paulo.

Na cidade de São Paulo, há dois grandes polos de comércio de roupas: Bom Retiro e Brás. Essa concentração maior de bolivianos está no entorno desses dois polos. A escola escolhida também se encontra na região de um desses polos, o Bom Retiro.

A escola é da rede estadual, oferece o ensino fundamental 2 (sexto ao nono ano) e o ensino médio. Segundo dados fornecidos pela coordenadoria da escola, um terço dos alunos é constituído por estrangeiros ou filhos de estrangeiros.

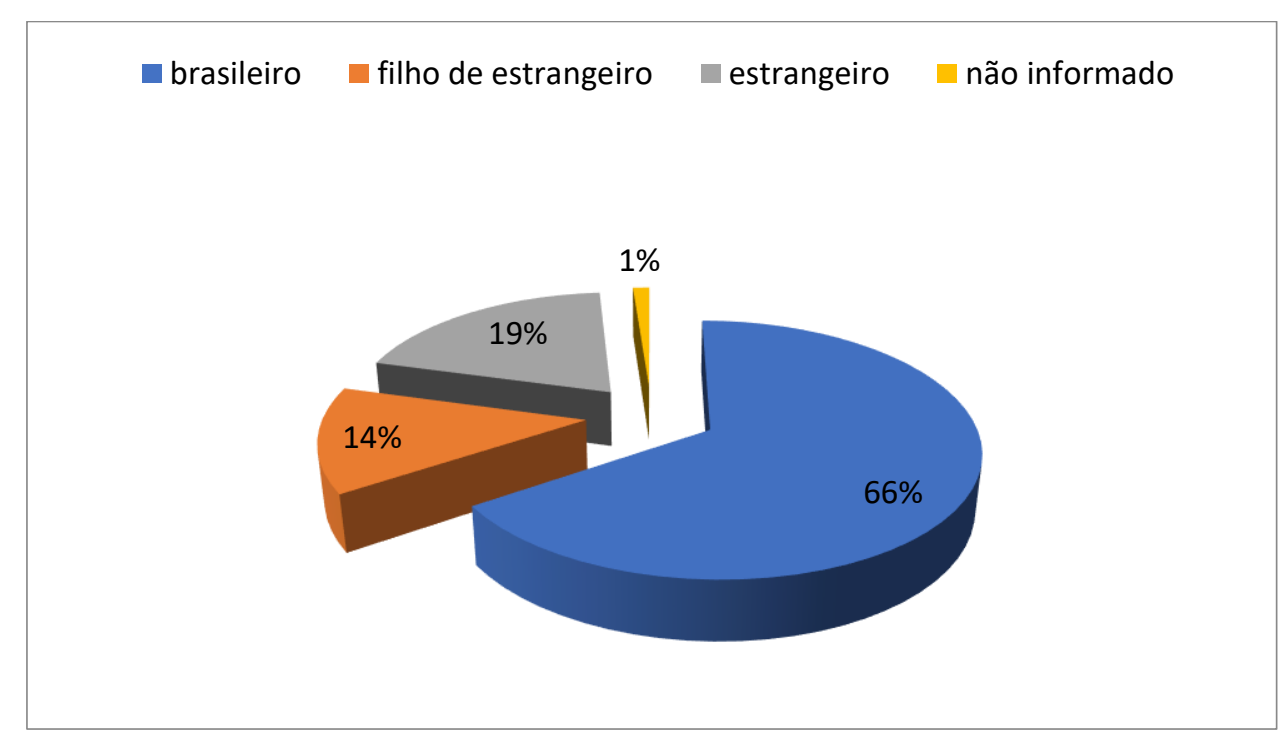

Fonte: Coordenação da escola analisada

Gráfico 1

Nacionalidade dos alunos da escola analisada 
Cadernos CERU, Série 2, Vol. 31, n. 1, jun. 2020

A observação foi realizada em duas turmas (oitavo e nono anos do ensino fundamental) uma vez por semana, sempre no mesmo dia e horário em cada uma das classes, por quatro semanas seguidas na disciplina de história. As classes tinham a seguinte concentração de alunos bolivianos e filhos de bolivianos, conforme mostram as tabelas 3 e 4 .

Tabela 3

Quantidade de alunos na turma do $8^{\circ}$. ano

\begin{tabular}{llll}
\hline \hline $8^{\circ}$. ano & Alunos & Alunas & Total \\
\hline Brasileiros & 7 & 15 & 22 \\
Filhos de bolivianos & 4 & 3 & 7 \\
Bolivianos & 1 & 1 & 2 \\
\hline Total & 12 & 19 & 31 \\
\hline
\end{tabular}

Tabela 4

Quantidade de alunos na turma do $9^{\circ}$. ano

\begin{tabular}{llll}
\hline \hline $9^{\circ}$. ano & Alunos & Alunas & Total \\
\hline Brasileiros & 9 & 11 & 20 \\
Filhos de bolivianos & 4 & 2 & 6 \\
Bolivianos & 2 & 4 & 6 \\
\hline Total & 15 & 17 & 32 \\
\hline
\end{tabular}

\section{Observação em classe}

\subsection{Multiculturalismo e interculturalismo}

Há uma grande discussão acadêmica sobre o significado das palavras: multiculturalismo, pluralismo cultural, cosmopolitismo e interculturalismo. Para Hall (2003), a palavra "multiculturalismo" normalmente é usada no singular e representa uma doutrina ou filosofia escolhida para lidar com os problemas de diversidades e multiplicidades decorrentes da sociedade multicultural. Mas Hall (2003) também nos alerta para a existência de uma diversidade de "multiculturalismos"; por exemplo, haveria um multiculturalismo conservador que busca a assimilação da diferença à cultura dominante; também haveria um 
Cadernos CERU, Série 2, Vol. 31, n. 1, jun. 2020

multiculturalismo liberal que enfatiza uma cidadania individual universal, aceitando as práticas divergentes em relação à cultura majoritária apenas no âmbito privado, além de outros tipos de multiculturalismos. Para Vita (2002), multiculturalismo também pode ser chamado de pluralismo. Para Lopes (2012), multiculturalismo também pode ser chamado de pluralismo cultural ou cosmopolitismo. Lopes (2012) diz que o multiculturalismo busca a coexistência de culturas diferentes no mesmo espaço social por meio do respeito às diferenças e da tolerância, já o interculturalismo entende a interação e diálogo entre as culturas. Backstrom e CastroPereira (2012) também assinalam que o interculturalismo implica o diálogo e o conhecimento mútuo das culturas.

Com base nesses conceitos de Lopes (2012) e de Backstrom e Castro-Pereira (2012), pode-se afirmar que alguns pesquisadores mostram que não há multiculturalismo nas escolas públicas pesquisadas por eles na cidade de São Paulo. Por exemplo, Fernandez (2015) relata que muitos bolivianos deixam a escola no ensino médio devido ao bullying que sofrem e se fecham em seu círculo de amizades dentro da colônia na região central da cidade de São Paulo e se encontram com outros jovens bolivianos aos domingos na Praça Kantuta ou nas festas para os latinos. Miyahira (2015) relata que há problemas de relacionamento entre os alunos brasileiros e alunos bolivianos na escola pesquisada em seu trabalho, apesar do discurso dos professores de que a convivência é harmônica. Oliveira (2013) também relata situações de conflito e perseguição:

(...) o aluno boliviano da 5a. série, H., que depois de ter seus pertences roubados por um colega de sala brasileiro passa a usar um grande cadeado em sua mochila para evitar novos furtos; ou ainda como outro aluno boliviano, A., da 6a. série que espera em pé todos os colegas na hora do recreio almoçarem para só então sentar-se à mesa, evitando assim a concretização da ameaça de que seus colegas brasileiros joguem sua comida em sua cabeça, como acontecido anteriormente. (Oliveira, 2013, p. 13).

Ao estudar os motivos para comportamentos de perseguição de membros de um grupo em relação a membros de outro grupo, Elias e Scotson (2000) perceberam que esse comportamento não está vinculado ao indivíduo somente. Esse comportamento está ligado ao grupo ao qual ele pertence. Esse sentimento de serem pessoas "melhores" está ligado a um sentimento de carisma grupal. Relaciona-se também ao grau de coesão interna e de controle comunitário do grupo que se sente superior. A estigmatização do grupo recém-chegado (outsiders) pelo grupo mais antigo (estabelecidos) é uma arma de preservação da identidade, mantendo os "outros" em seu "respectivo lugar". O que mantém essa situação é o desequilíbrio de poder na relação entre os grupos. Esse poder não está relacionado necessariamente ao tamanho do grupo. Para provar isso, Elias e Scotson (2000) descrevem a história de um pequeno 
Cadernos CERU, Série 2, Vol. 31, n. 1, jun. 2020

grupo que entrou na Índia pelo Norte, que falava uma língua indo-europeia e que se descrevia como arianos de pele clara. Esse grupo estabeleceu uma relação de poder com a população da Índia, considerando-se "superiores". A população da Índia aceitou essa descrição de serem "inferiores" mesmo sendo numericamente maior. Esse fato perseverou mesmo depois que as características físicas distintas desse grupo menor deixaram de existir. Como não havia muitas mulheres no grupo menor, eles permitiram a relação com as mulheres "subjugadas", fazendo com que diminuíssem as diferenças físicas com o tempo, mas isso não diminuiu o preconceito entre os grupos. Elias e Scotson (2000) também descrevem que a relação de poder que sustenta a relação entre os estabelecidos e os outsiders não se baseia necessariamente na condição financeira. No caso estudado pelos autores na cidade de Winston Parva, não era isso que diferenciava os grupos e mesmo assim havia uma perseguição pelo grupo mais antigo (estabelecidos) ao grupo mais novo (outsiders). Elias e Scotson (2000) também relatam o caso dos "Burakumin" no Japão. Apesar de alguns "Burakumin" estarem em uma posição social acima dos outros japoneses, alguns deles eram tão pobres quanto os outros japoneses, mas o sentimento de superioridade permanecia. O estigma que os estabelecidos impõem aos outsiders também não se relaciona com as características físicas, segundo Elias e Scotson (2000). Pelo contrário, as características físicas são usadas para "objetivar" os estigmas. Quando não há essa diferenciação física, o grupo estabelecido pode criar uma. Elias e Scotson (2000) citam novamente o exemplo dos "Burakumin" no Japão. Muitos japoneses diziam que os "Burakumin" possuem um sinal hereditário, uma mancha azulada abaixo das axilas, com o intuito de "objetivar" e "naturalizar" a "superioridade". Pois, assim, se desloca o motivo da inferiorização do campo das relações de poder para a natureza do indivíduo. A capacidade de estigmatização de um grupo sobre o outro relaciona-se com a diferença acentuada na coesão interna dos dois grupos e a relação assimétrica de poder entre eles. Uma ilustração desse fato é a incapacidade dos grupos outsiders de também estigmatizar o grupo estabelecido. Os insultos não têm como envergonhar os membros de um grupo estabelecido, pois o equilíbrio de poder é desigual.

Assim, entendemos que a estigmatização dos brasileiros sobre os imigrantes bolivianos só é possível se a socialização na escola reconhecer aos brasileiros (estabelecidos) um poder maior do que aos imigrantes (outsiders). Nessa relação, entendemos que os professores e a direção da escola tem um papel importante, podendo regular e equilibrar essa questão. Porém, segundo alguns pesquisadores, por exemplo Fernandez (2015), Oliveira (2013) e Miyahira (2015), algumas escolas públicas adotam uma postura de indiferença. Algumas escolas ignoram as especificidades dos alunos estrangeiros em nome de um tratamento "igualitário". Portanto, 
Cadernos CERU, Série 2, Vol. 31, n. 1, jun. 2020

não se faz nenhum trabalho para igualar os poderes nas relações; pois, na visão dessas escolas, isso seria discriminar os alunos. Porém, deixando para que os próprios alunos construam suas relações e a sua socialização, há uma grande possibilidade de os alunos brasileiros estabelecerem uma relação de poder e submissão com os estrangeiros e fazerem bullying com os mesmos. Diante dessa questão é importante o entendimento da diferença entre "igualdade" e "equidade".

Em sua formulação clássica, a igualdade enfatiza os elementos comuns aos indivíduos genéricos e não suas diferenças, seus particularismos coletivos, ela remete sempre a uma concepção global e comum da sociedade. É diferente o que se dá com a noção de "equidade" que reconhece a pertinência política das especificidades culturais dos indivíduos e dos grupos, aceitando a ideia de um tratamento diferenciado dos membros dessas coletividades. (MARTUCCELLI, 1996, p. 21).

Assim, para que haja um equilíbrio na relação entre os dois grupos (brasileiros e imigrantes) nas escolas públicas de São Paulo, é preciso uma ação que busque a equidade, ou seja, tratar diferentemente os diferentes para que haja equilíbrio nas relações de poder.

Segundo Flores (2017), tratar como iguais os desiguais não promove a igualdade, pelo contrário, promove a desigualdade. É necessário realizar ações compensatórias para dar mais a quem tem menos. Dubet (2004) também destaca que nos sistemas escolares há muitas desigualdades, portanto, adotar um sistema "meritocrático" não seria justo. Para se obter mais justiça, é preciso que a escola considere as desigualdades e procure compensá-las por meio de uma discriminação positiva (DUBET, 2004).

Flores (2017) e Dubet (2004) referem-se ao processo de aprendizagem, assim, esses conceitos se aplicariam muito bem no que se refere ao aprendizado do idioma português por parte dos estrangeiros, por exemplo. Mas acreditamos que o mesmo princípio também pode ser aplicado aos processos de socialização dentro da escola, criando-se uma regulação ou uma discriminação positiva nas relações de poder que se estabelecem na socialização entre os alunos.

\subsection{Dados observados em classe}

Durante as quatro semanas de observação, não notamos nenhuma situação de conflito ou perseguição aos bolivianos por parte dos alunos brasileiros. Também verificamos intervenções dos professores na busca de equidade entre os alunos bolivianos e brasileiros. $\mathrm{Ou}$ seja, já é uma postura diferenciada das relatadas em pesquisas anteriores, nas quais se buscava somente a "igualdade" entre os alunos. 
Cadernos CERU, Série 2, Vol. 31, n. 1, jun. 2020

Um exemplo de uma atitude dos professores em busca de equidade ocorreu na turma do oitavo ano. Havia um aluno recém-chegado da Bolívia e, assim que o professor soube disso, tomou algumas medidas: pediu para o aluno sentar a sua mesa para conversar um pouco, depois pediu para um aluno brasileiro ser o seu "tutor" ajudando-o nas tarefas e disse que o aluno estrangeiro poderia fazer as tarefas em espanhol mesmo.

Porém, durante a observação nas duas turmas verificamos que os alunos bolivianos ou filhos de bolivianos interagiam pouco com os alunos brasileiros. Eles costumavam sentar próximos uns dos outros, separados somente pelo gênero (Diagrama 1). Ou seja, os meninos sentam juntamente com os meninos e as meninas, com as meninas. Já os alunos brasileiros se misturavam mais nesse quesito de gênero. Em uma das classes observadas (oitavo ano), as meninas bolivianas ou filhas de bolivianos sempre se sentavam na primeira fileira do lado esquerdo da sala, nas primeiras carteiras, e uma delas sentava na segunda fileira (em relação ao aluno que estava olhando em direção à lousa). Essa aluna da segunda fileira aproximava a sua carteira da carteira da aluna da primeira fileira. Já os meninos bolivianos ou filhos de bolivianos, nessa mesma classe, sempre se sentavam na fileira do meio, um atrás do outro, e um deles na fileira do lado direito. O aluno boliviano que acabara de chegar da Bolívia sentava junto com o seu "tutor" em frente à mesa do professor.

\section{Diagrama 1}

Disposição dos alunos na classe - 80 .

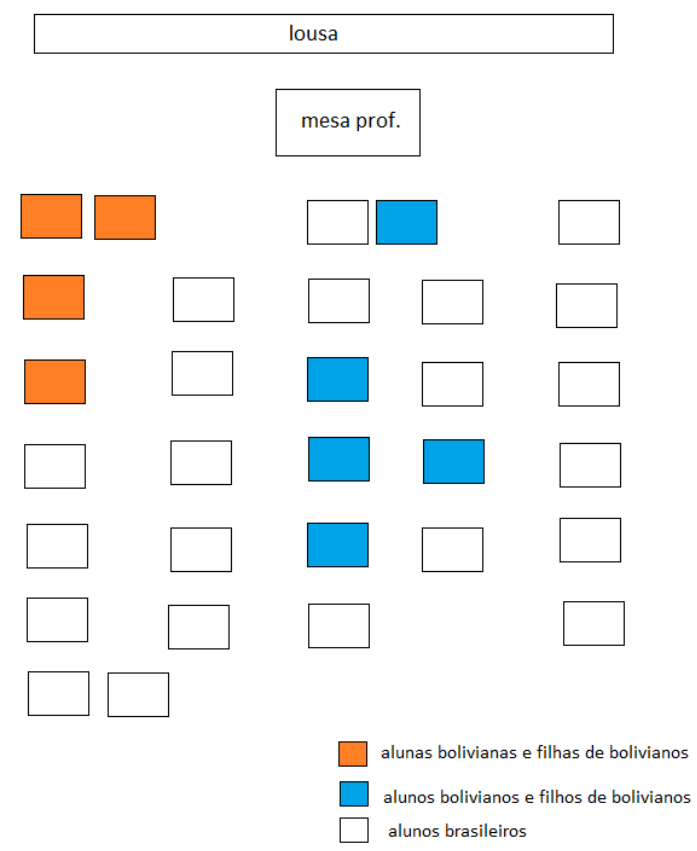

Na outra turma observada (nono ano), também verificamos essa separação: alunos bolivianos e filhos de bolivianos sentados junto, e também separados pelo gênero, os meninos 
com os meninos e as meninas com as meninas. Mas, de qualquer forma, apesar dessa separação por gênero, verifica-se que os alunos estrangeiros ainda preferiam sentar-se sempre juntos e, durante todas as aulas observadas, preferiam interagir somente entre si.

Assim, entendemos que a escola conseguiu implantar uma convivência multicultural segundo o conceito de Lopes (2012), na qual há a coexistência de culturas diferentes no mesmo espaço social por meio do respeito às diferenças e da tolerância. Mas parece que a escola ainda não conseguiu uma convivência intercultural, onde também haja uma interação e diálogo entre as culturas além da convivência pacífica.

Silva (2014) relata que há quatro possibilidades para as escolas tratarem pedagogicamente a questão das identidades. A primeira, chamada de "liberal", seria o cultivo por parte da escola de bons sentimentos quanto à diversidade cultural. A escola levaria os alunos a terem contato com as mais variadas formas e expressões culturais. Porém, Silva (2014) alerta para o fato de que essa posição, muitas vezes, não questiona as relações de poder e, assim, se criam novas dicotomias: dominante tolerante e dominado tolerado. Na segunda possibilidade, descrita por Silva (2014) como "terapêutica", a escola aceita a diversidade, mas atribui a rejeição das diferenças a questões psicológicas. Assim, o tratamento mais adequado seria a conscientização por meio de atividades pedagógicas levando os estudantes a mudarem suas atitudes. A terceira possibilidade, segundo Silva (2014), seria uma alternativa intermediária entre as duas anteriores. As diferentes culturas são apresentadas de forma superficial e o outro ainda pode ser visto como exótico. Como última possibilidade, Silva (2014) apresenta a alternativa que julga ser a melhor. Nessa alternativa, a identidade e a diferença são tratadas como questões políticas, ou seja, analisa-se a diferença como uma produção social. Também se questiona como as identidades são construídas e quais os mecanismos e as instituições que estão envolvidos na criação da identidade.

$\mathrm{Na}$ escola analisada, faltou um aprofundamento no questionamento juntamente com os alunos sobre os mecanismos envolvidos na criação da identidade e no estabelecimento das relações de poder.

\subsection{Modelo de aluno}

Algumas pesquisas definem os alunos bolivianos como alunos submissos à autoridade do professor. Miyahira (2015) relata que na escola onde realizou sua pesquisa, na zona oeste da cidade de São Paulo, havia um forte contraste entre o comportamento mais submisso dos alunos bolivianos em comparação com os alunos de origem do Nordeste do Brasil. Ele também relatou que as famílias bolivianas valorizavam muito a figura do professor e orientavam 
Cadernos CERU, Série 2, Vol. 31, n. 1, jun. 2020

constantemente seus filhos a respeitar o mesmo. Oliveira (2013) também comenta que na escola onde realizou sua pesquisa, na região norte da cidade de São Paulo, havia uma diferença na forma como os alunos brasileiros e os alunos bolivianos se dirigiam ao professor. Os alunos bolivianos eram muito mais formais e, quando se dirigiam ao professor, o faziam com a cabeça baixa e com a voz baixa. Já os alunos brasileiros se dirigiam de forma mais informal e menos respeitosa.

Como resultado, segundo esses dois pesquisadores, criou-se uma visão do aluno boliviano como um aluno "exemplar" nessas duas escolas. Pelo menos, são descritos como alunos que não causam problemas durante as aulas. Oliveira (2013), inclusive, relata que alguns professores comentaram que até achavam interessante o isolamento dos alunos bolivianos e que não desejavam se desgastar com o problema de bullying; pois, caso o aluno se socializasse melhor, poderia passar a conversar mais durante a aula e atrapalhar o trabalho do professor.

Aquino (1998) comenta que boa parte dos professores, em sua opinião, ainda busca como ideal a escola de antigamente na qual o bom aluno é o aluno calado, imóvel e obediente. Aquino (1998) acredita que a indisciplina presente nas escolas indica a necessidade de transformação na relação professor-aluno e nas relações dentro da escola. Ele combate a ideia de muitos professores de que é necessário primeiro uma normatização moral dos hábitos das crianças para, posteriormente, se fazer o trabalho na área do pensamento.

Durante as observações, tivemos um exemplo prático de que essa ideia de os bolivianos ou filhos de bolivianos serem bons alunos pelo simples fato de serem mais calados e não trazerem problemas nem sempre se concretiza. Mesmo porque estamos tratando de indivíduos com escolhas próprias, apesar de estarem inseridos na cultura de seu grupo. Ou seja, nem sempre o fato de o aluno ser mais reservado e calado o faz um aluno mais empenhado no aprendizado. Durante as observações em classe, verificamos que normalmente os alunos brasileiros conversavam bastante e em voz alta, já os alunos bolivianos não chamavam a atenção do professor. As meninas bolivianas ou filhas de bolivianos ficavam juntas o tempo todo e pareciam mais dedicadas aos estudos e às tarefas. Já alguns dos meninos bolivianos ou filhos de bolivianos escutavam música durante a aula. Em uma das aulas, dois alunos bolivianos assistiam a vídeos legendados em espanhol no YouTube no momento da tarefa na sala de informática e, quando o professor se aproximava, eles abriam outra tela. $\mathrm{O}$ uso do celular durante a aula também foi verificado tanto por alunos brasileiros quanto por alunos bolivianos, em muitos casos, mesmo durante as explicações do professor.

Mas, de fato, os alunos bolivianos eram um pouco mais "invisíveis" durante as aulas. Por exemplo, quando o professor perguntava se alguém tinha alguma dúvida, nenhum imigrante 
ou filho de imigrante levantava a mão ou fazia perguntas. Somente alunos brasileiros questionavam o professor. Houve uma única vez em que uma aluna boliviana fez uma pergunta ao professor, levantou a mão e, após o consentimento do professor, se levantou e foi até próximo dele para fazer a pergunta ao mesmo. Diferentemente da maioria dos alunos brasileiros que perguntavam sem antes pedir permissão e o faziam em voz alta.

Também verificamos que o professor não pedia que os alunos bolivianos ou filhos de bolivianos participassem da aula pronunciando-se publicamente. Um exemplo foi quando o professor pediu para alunos lerem as questões da prova, todos os alunos escolhidos eram brasileiros. Somente os alunos brasileiros também fizeram comentários e intervenções durante a correção das questões. Ou seja, os alunos estrangeiros ou filhos de estrangeiros não foram requisitados nem se voluntariaram a participar publicamente da atividade.

Assim, verificamos que os alunos são discretos e não atrapalham o andamento das aulas. Porém, nem sempre esse comportamento mais comedido se reflete em uma dedicação maior aos estudos. Parece-nos que a preocupação maior dos professores é com relação a manutenção da ordem durante as aulas e não necessariamente com o maior aprendizado dos alunos.

\subsection{Práticas pedagógicas}

Sayad (2010) diz que o imigrante é obrigado a esquecer sua história no país de origem e se adaptar à nova cultura. Assim, ele passa por um conflito, já que, ao mesmo tempo em que tem sua identidade apagada, carrega em seu corpo e em seus códigos o país de origem. Porém, como já vimos, Lopes (2012) diz que o interculturalismo entende a interação e diálogo entre as culturas e Backstrom e Castro-Pereira (2012) dizem que o interculturalismo implica o diálogo e o conhecimento mútuo das culturas. Mas a questão é se as práticas pedagógicas da escola observada buscam esse interculturalismo de forma intencional ou simplesmente forçam o aluno estrangeiro a apagar sua memória, cultura e valores nesse processo de ressocialização.

Martuccelli (1996) relata que, na sociedade atual, os indivíduos já não se satisfazem com a expressão de suas particularidades somente no âmbito privado como ocorria anteriormente. Os indivíduos desejam expressar sua identidade individual no âmbito público também, rompendo com o conceito liberal do homem público universal que lançava as particularidades para o âmbito privado. Martuccelli (1996) também afirma que é necessária uma mudança no conceito de igualdade, pois não é mais possível pensar a igualdade no interior de uma concepção global de injustiça, onde se desloca a mesma para o conceito de igualdade de oportunidades. A sociedade demanda uma igualdade que se realize de fato e para tanto, em muitos casos, é necessária a utilização do conceito de equidade (MARTUCCELLI, 1996). 
Assim, se antes o Estado intervinha de maneira universalista, agora é preciso que introduza igualdade de direitos em função da situação particular de cada um. Segundo Martuccelli (1996, p. 23) "[...] não se trata mais de aplicar os mesmos princípios a todo o mundo e, às vezes, nem se concebe mais que os princípios sejam idênticos para todo o mundo: trata-se sempre de levar em conta as circunstâncias pessoais."

Esse dilema também se manifesta na escola. A concepção laica de escola defende que o individuo deva despir-se de suas particularidades e ser um cidadão a ser formado na escola. Por outro lado, há quem deseje a escola como um espaço de afirmações identitárias, onde o desejo de expor publicamente a sua individualidade seja acolhido (MARTUCCELLI, 1996).

A escola tem um papel essencial na disseminação de uma sociedade multicultural ou intercultural. Sansone (2003), em seu estudo sobre as políticas públicas desenvolvidas em alguns países europeus que receberam forte imigração, salienta que o serviço público é a esfera em que se experimentam medidas em prol de minorias e a escola pública é o palco principal pró-diversidade do multiculturalismo.

Mas, na prática, vemos as dificuldades que as três escolas públicas de São Paulo pesquisadas anteriormente enfrentaram para implantar uma agenda multicultural ou intercultural. Miyahira (2015) relata:

A presença de alunos com diversos sotaques e de alunos de língua espanhola na escola poderia levar a um trabalho de reconhecimento destas culturas e de trocas entre os alunos. Para os maiores, poderia inclusive haver discussão sobre estas relações de poder e a influência que elas exercem sobre a estética e sobre os gostos. Porém, na prática, não é isso que acontece. Os professores ignoram todas as diferenças e dão as aulas como se a turma fosse constituída de um único perfil de aluno. Todos os professores entrevistados expressam que tratam todos os alunos pedagogicamente da mesma forma. Inclusive expressam esta ideia com alegria, considerando que assim, não fazem discriminação. (Miyahira, 2015, p. 85).

Oliveira (2013) também se deparou com essa forma de pensar em duas escolas onde realizou sua pesquisa. Lá, os funcionários também acreditam que todos devem ser tratados igualmente e levam essa orientação ao pé da letra. Oliveira (2013) deparou-se com a indignação dos funcionários das duas escolas ao lhes perguntar quantos alunos bolivianos havia nas mesmas. Os funcionários disseram que não se fazia diferenças naquelas escolas, ou seja, eles entendiam que o simples contar quantos alunos nasceram no Brasil e quantos nasceram na Bolívia seria uma forma de fazer distinção entre os alunos. Para eles, isso seria um ato preconceituoso.

Soares e Silva (2013) relatam que o conceito de igualdade é um consenso na escola e que aparece muito claramente nas entrevistas. Porém, esse conceito de igualdade é formulado 
Cadernos CERU, Série 2, Vol. 31, n. 1, jun. 2020

de tal modo que impede o reconhecimento das diferenças e impede a realização de qualquer ação diferenciada para os alunos que sofrem algum preconceito.

Nas observações em classe realizadas, constatamos algumas ações que buscavam essa equidade por meio de práticas pedagógicas com esse intuito. Um exemplo, já citado acima, foi o caso de um aluno boliviano que acabara de chegar da Bolívia e que recebeu um tratamento diferenciado por parte do professor para ajudá-lo em sua adaptação em classe. O professor o chamou para conversar, elegeu um aluno brasileiro como "tutor" a fim de auxiliá-lo nas tarefas e permitiu que fizesse as lições em espanhol. Essa ação pareceu dar bom resultado. Nas aulas seguintes, observamos que esse aluno estrangeiro se mostrava bastante à vontade com a companhia do aluno brasileiro que era seu "tutor".

Porém, também observamos situações que poderiam ser aproveitadas para essa maior interação. Um exemplo observado no oitavo ano, foi quando o professor pediu para que se formassem duplas para uma tarefa. Os próprios alunos deveriam formar os grupos. Assim, os alunos bolivianos ou filhos de bolivianos formaram duplas entre si. As exceções foram somente uma aluna boliviana que se juntou com uma brasileira, pois as meninas estavam em número ímpar e o aluno que era acompanhado pelo seu "tutor" que realizou a tarefa com o mesmo.

Assim, vemos que essa escola observada adota práticas mais próximas de uma busca de equidade entre os alunos em comparação com as escolas pesquisadas em outros trabalhos: Soares e Silva (2013), Oliveira (2013) e Miyahira (2015). Porém, ainda há muitas oportunidades que poderiam ser aproveitadas com esse intuito.

\section{Considerações finais}

Este breve texto mostrou que a escola pesquisada da rede estadual de ensino da cidade de São Paulo já está despertando para a importância de uma prática pedagógica mais equitativa e de uma busca de relações mais equilibradas entre os brasileiros e os estrangeiros, buscando um ambiente multicultural. Porém, baseados nos conceitos de Lopes (2012) que diz que o multiculturalismo busca a coexistência de culturas diferentes no mesmo espaço social por meio do respeito às diferenças e da tolerância, mas o interculturalismo entende a interação e diálogo entre as culturas, ou baseados no conceito de Backstrom e Castro-Pereira (2012) que diz que o interculturalismo implica o diálogo e o conhecimento mútuo das culturas, vemos que esta escola ainda não alcançou a construção de um ambiente intercultural. Para tanto, poderia realizar muitas outras práticas pedagógicas com esse intuito como: a discussão da estética e como a mesma é relativa, a análise das mesmas raízes etimológicas das palavras de diversos idiomas, a discussão da importância da pluralidade na construção de um pensamento, a análise da 
semelhança histórica na formação dos países de toda a América Latina. Poder-se-ia abordar um currículo que questionasse as relações de poder já estabelecidas, porém sem deixar de lado o currículo que a escola já exige que todos os alunos aprendam.

Também verificamos que a imagem do aluno boliviano ou filho de boliviano como um aluno exemplar, muitas vezes é baseada no fato de não perturbar o andamento da aula e não necessariamente em ser um aluno com bom desempenho acadêmico.

Esperamos que este breve texto ajude no estudo desta questão. Mas também reconhecemos que ainda há muito o que se verificar e analisar na relação entre esses dois grupos nos processos escolares.

\section{Bibliografia}

AQUINO, J. G. (1998). A indisciplina e a escola atual. Disponível em: 〈http:www.scielo.br>. Acesso em: 23 abr. 2019.

BACKSTROM, B.; CASTRO-PEREIRA, S. (2012). "A questão migratória e as estratégias de convivência entre culturas diferentes em Portugal". Revista Interdisciplinar da Mobilidade Humana. Brasília, ano XX, n. 38, jan/jun. 2012. p. 83-100.

DUBET, F. (2004). "O que é uma escola justa?". Cadernos de Pesquisa, São Paulo, Fundação Carlos Chagas, v. 34, n.123, set/dez. p. 539-555.

ELIAS, N.; SCOTSON, J. L. (2000). Os estabelecidos e os outsiders. Rio de Janeiro: Zahar.

FERNADEZ, C. C. G. (2015). Entre dois países, sonhos e ilusões: trajetórias de e/imigrantes bolivianos em São Paulo (1980-2000). Tese (Doutorado), Pontifícia Universidade Católica de São Paulo, São Paulo.

FLORES, G. C. (2017). "Igualdad y equidad en educación: retos para una America Latina en transición". Educación. vol. XXVI, n. 51, sept. 2017. p.159-178.

HALL, S. (2003). Da diáspora - identidades e mediações culturais. Belo Horizonte: UFMG/ Brasília: Representação da UNESCO no Brasil.

LOPES, A. M. D. (2012). "Da coexistência à convivência com o outro: entre o multiculturalismo e a interculturalidade". Revista Interdisciplinar da Mobilidade Humana. Brasília, ano XX, n. 38, jan/jun. p. 67-81.

MARTUCCELLI, D. (1996). "As contradições políticas do multiculturalismo". Revista Brasileira de Educação. mai/jun/jul/ago, n. 2, p. 18-32.

MIYAHIRA, E. (2015). Relação entre professor e família: um estudo sobre alunos bolivianos e nordestinos na escola pública. Dissertação (Mestrado), Pontifícia Universidade Católica de São Paulo, São Paulo.

OLIVEIRA, L. R. P. (2013). Encontros e confrontos na escola: um estudo sobre as relações sociais entre alunos brasileiros e bolivianos em São Paulo. Dissertação de mestrado, Pontifícia Universidade Católica de São Paulo, São Paulo.

SANSONE, L. (2003). "Multiculturalismo, Estado e modernidade: as nuanças em alguns países europeus e o debate no Brasil". DADOS - Revista de Ciências Sociais. Rio de Janeiro, vol. 46, n. 3, p. 535-556. 
SAYAD, A. (2010). La doble ausencia - De las ilusiones del emigrado a los padecimentos del inmigrado. Barcelona: Anthropos editorial.

SILVA, T. T. (2014). "A produção social da identidade e da diferença". In: SILVA, T. T. (Org.). Identidade e diferença - a perspectiva dos estudos culturais. Petrópolis: Vozes, p. 73-102.

SOARES, L. N.; SILVA, S. A. (2013). "Relações étnico-raciais e educação infantil: ouvindo crianças e adultos". Anais da $36^{a}$ R.N. ANPED. Goiânia: ANPED.

VITA, A. (2002). "Liberalismo igualitário e Multiculturalimo". Lua Nova. n. 55-56, p. 5-27.

XAVIER, I. R. (2012). "A inserção socioterrritorial de migrantes bolivianos em São Paulo. Uma leitura a partir da relação entre projetos migratórios, determinantes estruturais e os espaços da cidade". In: BAENINGER, R. (Org.) Imigração boliviana no Brasil. Campinas: Núcleo de Estudos de População - NEPO/Unicamp, p. 109-153. 